Article

\title{
High-Resolution Mapping of Freeze/Thaw Status in China via Fusion of MODIS and AMSR2 Data
}

\author{
Tongxi Hu ${ }^{1,2}$ (D) , Tianjie Zhao ${ }^{2, *}$, Jiancheng Shi ${ }^{2}$, Shengli $\mathrm{Wu}^{3}$, Dan Liu ${ }^{1}$, Haiming Qin ${ }^{2,4}$ and \\ Kaiguang Zhao 1,4,* \\ 1 Environmental Science Graduate Program, The Ohio State University, Columbus, OH 43210, USA; \\ hu.1555@osu.edu (T.H.); liu.6253@osu.edu (D.L.) \\ 2 State Key Laboratory of Remote Sensing Science, Institute of Remote Sensing and Digital Earth, \\ Chinese Academy of Sciences, No. 20 Datun Road, Beijing 100101, China; shijc@radi.ac.cn (J.S.); \\ qin.434@osu.edu (H.Q.) \\ 3 National Satellite Meteorological Center, Beijing 100081, China; wusl@cma.gov.cn \\ 4 School of Environment and Natural Resources, OARDC, The Ohio State University, Columbus, OH 43210, USA \\ * Correspondence: zhaotj@radi.ac.cn (T.Z.); zhao.1423@osu.edu (K.Z.); Tel.: +1-330-263-3722 (K.Z.)
}

Received: 30 October 2017; Accepted: 13 December 2017; Published: 20 December 2017

\begin{abstract}
Transition of freeze/thaw (F/T) affects land-atmospheric interactions and other biospheric dynamics. Global F/T statuses are normally monitored using microwave remote sensing, but at coarse resolutions (e.g., $25 \mathrm{~km}$ ). Integration of coarse microwave remote sensing data with finer satellite products represents an opportunity to further enhance our ability to map F/T statuses regionally and globally. Here, we implemented and tested an approach to generate daily $\mathrm{F} / \mathrm{T}$ status maps at a 5-km spatial resolution through the fusion of passive microwave data from AMSR2 and land surface temperature products from MODIS, using China as our study area for the year 2013 and 2014. Moreover, possible influences from elevation, vegetation, seasonality, etc., were also analyzed, as such analysis provides a direction to improve the approach. Overall, our freeze/thaw maps agreed well with ground reference observations, with an accuracy of $\sim 86.6 \%$. The new F/T maps helped to identify regions subject to frequent $\mathrm{F} / \mathrm{T}$ transitions through the year, such as the Qinghai-Tibetan Plateau, Xinjiang, Gansu, Heilongjiang, Jilin, and Liaoning Province. This study indicates that the combination of AMSR2 and MODIS observations provides an effective method to obtain finer F/T maps (5-km or lower) for extensive regions. The finer F/T maps improve our knowledge of the F/T state detected by satellite remote sensing, and have a wide range of applications in regional studies considering land surface heterogeneity and models (e.g., community land models).
\end{abstract}

Keywords: high-resolution freeze/thaw; AMSR2; MODIS

\section{Introduction}

About $55 \%$ of the exposed land surface in the northern hemisphere experiences freeze/thaw (F/T) transitions annually [1]. These transitions occur within the upper permafrost layers and frozen grounds that react sensitively to climate and environmental changes. By controlling water and heat flux exchange at the land-atmosphere interface, $\mathrm{F} / \mathrm{T}$ status imposes a significant constraint on ecosystem processes $[2,3]$ and vegetation growth $[4,5]$, resulting in important impacts on surface water, and the nitrogen [6] and carbon cycle [7]. To evaluate these ecological or hydrological impacts accurately, data of the F/T status with high spatial and temporal resolutions are essential [8]. However, observations of the $\mathrm{F} / \mathrm{T}$ status with high spatial and temporal resolution in a global or regional scale are still unavailable. Traditional in situ observations or numerical modeling could provide accurate point measurements for the investigation of F/T transitions [9], but these conventional methods are limited to regional areas with continuous coverage. Instead, remote sensing data, especially microwave remote 
sensing, has provided a chance to detect the F/T status in recent years. The foundation of detecting the $\mathrm{F} / \mathrm{T}$ status by microwave remote sensing is the distinct contrast between dielectric properties that occurs when water transitions between solid and liquid [10], which means the phase of soil water during the F/T transitions will severely affect the sensitivity of radiometer brightness temperature $(\mathrm{Tb})$ and radar backscatter signatures.

Based on the dramatic changes of the signal on the F/T status observed by passive microwave sensors, many approaches have been developed. Most of these approaches, such as dual-index [9], decision tree [11], seasonal threshold [4,12], and discriminant function algorithm (DFA) [13], combine observations from multiple channels from a specific sensor, for example, SSM/I, AMSR-E, AMSR2, SMMIS, etc., to capture the changes of soil temperature and moisture during F/T transitions. However, the $\mathrm{F} / \mathrm{T}$ status derived using passive microwave remote sensing suffers from a coarse spatial resolution of 0.25 degrees (about $25 \mathrm{~km}$ at the equator). Data or products with such a coarse resolution are no longer applicable for hydro-meteorological and agricultural studies [14]. High-resolution data are needed for a deeper understanding of processes that link to the terrestrial water, energy, and carbon cycles, as well as for significant improvement in numerical models, such as weather prediction and seasonal climate, flood and drought forecasting, crop yield estimating models, etc., that relate to land surface heterogeneity $[8,14,15]$.

Backscatter signatures from active remote sensors, such as satellite- or aircraft-based radar and scatterometers, are also able to capture signal changes during F/T transitions. Daily frozen and non-frozen statuses of Alaska were determined by Kimball et al. [5] with temporal change detection analysis relying on NASA scatterometer observations. A similar method was also used by Du et al. [15] to classify F/T status over Alaska based on Polarimetric SAR data with a spatial resolution of about $100 \mathrm{~m}$. Zwieback et al. [16] developed a statistical model to detect frozen soils using Advanced Scatterometer data and ERA Interim temperatures. Usually, observations acquired from active microwave remote sensing have a high spatial resolution (several kilometers or less). However, these observations are still limited to regional areas, as well as long revisit periods that are not feasible to monitor F/T transitions.

To overcome the limitations introduced by purely relying on passive or active remote sensing, a combination of multi-source remote sensing data for F/T retrieval has been recently studied for two satellite missions. One is the Soil Moisture Active Passive (SMAP) mission initiated to map the F/T status with a high spatial resolution of $2-3 \mathrm{~km}$ covering high northern latitude $\left(>45^{\circ} \mathrm{N}\right)$ areas and a short revisit period of 2-3 days by combining its active and passive measurements [8]. Unfortunately, the radar equipped on the satellite failed to work after operations of about three months, so the F/T maps are produced at a resolution of about 25 miles with just its radiometer now. The other satellite mission, Water Cycle Observation Mission (WCOM), aims to obtain the F/T status globally with a resolution of less than $5 \mathrm{~km}[17,18]$ relying on both innovative theory and techniques for retrieval and new sensing payloads. The payload configuration of the WCOM is a combination of active and passive, wide frequency coverage, microwave remote sensors. Although the combination of passive and active microwave remote sensing is promising to provide high-resolution $\mathrm{F} / \mathrm{T}$ maps covering a large area, such a map is still presently unavailable.

Instead of combining active and passive microwave observations, a recent experiment of fusing thermal and passive microwave remote sensing shows potential to obtain the $\mathrm{F} / \mathrm{T}$ status at a fine spatial resolution [17]. Classification of the F/T status by remote sensing is based on changes in two main aspects of the soil: water content and temperature. The changes of the soil water content can be captured by passive microwave bands. And the soil temperature can be measured by both thermal and microwave bands. The overlapping temperature information makes it possible to fuse observations from sensors of these two bands. Both thermal and microwave sensors have their own advantages. Thermal remote sensing data may suffer from many limitations, such as long revisit time periods (8-16 days) in boreal regions, but they have higher spatial resolutions compared with data from passive microwave remote sensing, for instance, the resolution of land surface temperature 
products derived from MODerate-resolution Imaging Spectroradiometer (MODIS) thermal bands can be as high as $1 \mathrm{~km}$. Passive microwave observations, such as brightness temperatures from AMSR2, have a coarse spatial resolution of $25 \mathrm{~km}$ at the equator, but they can capture dynamics during the $\mathrm{F} / \mathrm{T}$ transition process in a short revisit period (2-3 days) over large areas. The fusion of thermal and passive remote sensing combines the relative strengths of thermal and passive microwave remote sensing for enhanced soil F/T mapping.

The overall objective of this article was to evaluate a method to obtain high-resolution F/T dataset (here "high-resolution" is compared to the spatial resolution of passive microwave observations) by taking advantage of current thermal and passive microwave remote sensing data in large regions, such as China. An algorithm developed for AMSR sensors, DFA, was applied to observations from AMSR2 to acquire coarse resolution maps of F/T. These F/T maps have a spatial resolution of 0.25 degree, the same to that of AMSR2 observations. Two variables, F and T score $\left(\mathrm{D}_{\mathrm{F}}\right.$ and $\left.\mathrm{D}_{\mathrm{T}}\right)$, were generated by the DFA for each pixel, and they were the criteria to determine if a pixel is frozen or thawing. The specific objectives of this study were to: (1) analyze the relationship between land surface temperature from MODIS and the two variables $\left(\mathrm{D}_{\mathrm{F}}\right.$ and $\mathrm{D}_{\mathrm{T}}$ ) calculated by DFA; (2) investigate the usage of this relationship over China; and (3) combine the MODIS land surface temperature with coarse $\mathrm{F} / \mathrm{T}$ datasets obtained from passive microwave observation (AMSR2) to generate the high-resolution F/T map of China (0.05 degree, around 5-km at the equator). Finally, the derived high-resolution F/T maps were verified by in situ soil temperatures at $0-\mathrm{cm}$ depth across China.

\section{Materials and Methods}

\subsection{Remote Sensing Observations}

Remote sensing observations used here are acquired from passive microwave and thermal sensors. The passive microwave remote sensing data are obtained from the Advanced Microwave Scanning Radiometer-2 (AMSR2) onboard the Global Change Observation Mission 1st-Water (GCOM-W1) satellite [18] which was launched on 18 May 2012. AMSR2 is equipped with the world's largest revolving space antenna to detect radiometry from the Earth with an appropriate 1450-km width in one scan, so its observation can cover almost $99 \%$ of the globe in two days. The observations are obtained in six different channels $(6.9,10.7,18.7,23.8,36.5$, and $89.0 \mathrm{GHz})$ with horizontal and vertical polarization, and twice daily at local times around 13:30 (ascending) and 1:30 (descending) at the equator. The detailed characteristics of AMSR2 were summarized in Table 1. Daily brightness temperatures $(\mathrm{Tb})$ can be obtained from both the National Snow and Ice Data Center (NSIDC) and the Japan Aerospace Exploration Agency (JAXA). The Tb used here were from GCOM-W1 Data Providing Service [19] and they are daily quarter-degree gridded (version 02) data in global coverage. In addition to $\mathrm{Tb}$, precipitation data are also used here to exclude raining areas because of their significant influence on microwave emission. The precipitation data are the Level 3 standard products (version 02) of AMSR2, which can also be obtained from the GCOM-W1 Data Providing Service.

Table 1. The characteristics of AMSR2.

\begin{tabular}{|c|c|c|c|c|c|c|c|}
\hline Central Frequency (GHz) & 6.925 & 10.65 & 18.7 & 23.8 & 36.5 & \multicolumn{2}{|c|}{89.0} \\
\hline $\operatorname{IFOV}(\mathrm{km})$ & $43 \times 75$ & $29 \times 51$ & $16 \times 27$ & $18 \times 32$ & $8.2 \times 14.4$ & $3.7 \times 6.5$ & $3.5 \times 5.9$ \\
\hline Polarization & & & Ho & ontal and & rtical & & \\
\hline Incidence Angle & & & & $55^{\circ}$ & & & \\
\hline Swath & & & & $1445 \mathrm{~km}$ & & & \\
\hline Dynamic Range (K) & & & & $2.7-340$ & & & \\
\hline
\end{tabular}

Thermal observations are daily land surface temperature (LST) products (MYD11C1, version 5) from MODIS, a key instrument aboard the Terra and Aqua satellites. MODIS carried on the Aqua satellite was selected for this study [20]. Since the orbit of MODIS on Aqua shares numerous characteristics, for instance, the equator crossing time, revisit period, etc., with that of AMSR2, 
these characteristics provide a unique opportunity to combine observations of these two sensors with less systematic differences. MODIS can provide observations in as many as 36 spectral bands to improve our understanding of global dynamics and processes occurring on the land, in the atmosphere, and in the ocean. The data from MODIS are processed at various levels ranging from level 0 to level 4. Products at level 3 of two years $(2013,2014)$ are used here, which includes both LST and quality assessment values at 0.05 degree latitude/longitude climate modelling grids (CMG, 7200 columns $\times 3600$ rows) covering the global area [20]. The LST of two years $(2013,2014)$ was selected to investigate its potential relationship with $\mathrm{D}_{\mathrm{F}}$ and $\mathrm{D}_{\mathrm{T}}$ that are used to classify the $\mathrm{F} / \mathrm{T}$ status. In addition to the land surface temperature data, ancillary data, such as the MODIS IGBP (International Geosphere-Biosphere Program) map, are also included to identify the areas with permanent snow.

\subsection{Meteorological Data}

Assessment of $\mathrm{F} / \mathrm{T}$ maps usually relies on in situ measurements. Soil temperatures at $0-\mathrm{cm}$ depth were collected from 2425 stations across China to evaluate the high-resolution F/T maps here. The temperature measurements are extracted from the datasets (SURF_CLI_CHN_MUL_DAY_V3.0) archived by China Meteorological Administration (CMA) [21]. Most of these meteorological stations have data records for more than one year, but not all of them have continuous records for every day of the year. Moreover, the temperatures are only measured by sensors on the ground four times (2:00, 8:00, 14:00, 20:00) daily. The records at 2:00 and 14:00 were chosen to compare with the F/T maps generated by satellite observations at 1:30 and 13:30, respectively. The comparison is based on our assumption that the $\mathrm{F} / \mathrm{T}$ status when the soil temperature measurements are conducted is approximate to that when the satellites pass over. Similar assumptions have also been made to verify accuracy of the $\mathrm{F} / \mathrm{T}$ status derived from satellite observations $[4,12,16]$. To make the assessment convincing, in situ temperature measurements in 2013 were chosen to evaluate the agreement with the F/T maps.

\subsection{Methods}

Our methodological framework (Figure 1) includes combining thermal and passive microwave remote sensing data to generate F/T maps in China and evaluating the accuracy of this approach using in situ ground temperatures.

\subsubsection{Discriminant Function Algorithm (DFA)}

DFA is developed specifically for AMSR-E and performs well to determine the land surface F/T status. This algorithm has been evaluated by Zhao et al. [13] using the 4-cm soil temperature on Qinghai-Tibetan Plateau and the result shows an overall classification accuracy of $86 \%$. It also has the highest accuracy compared with two other algorithms, dual index [9] and decision tree algorithm [11], when applied to AMSR-E data [22]. In addition, further validation of this algorithm was conducted in our previous work using in situ air temperature measurements from the World Meteorological Organization (WMO, $88.37 \%$ and $82.76 \%$ for observations at $1: 30$ and $13: 30$, respectively), $0-5 \mathrm{~cm}$ soil temperature from International Soil Moisture Network (ISMN, 86.63\%), as well as modelled soil temperature by the Global Land Data Assimilation System (GLDAS, $89.74 \%$ and $87.6 \%$ for observations at 1:30 and 13:30, respectively) [23]. 


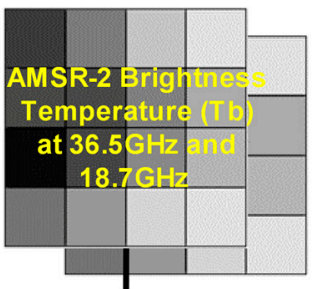

Calculate Freeze/Thaw Index (FTI)
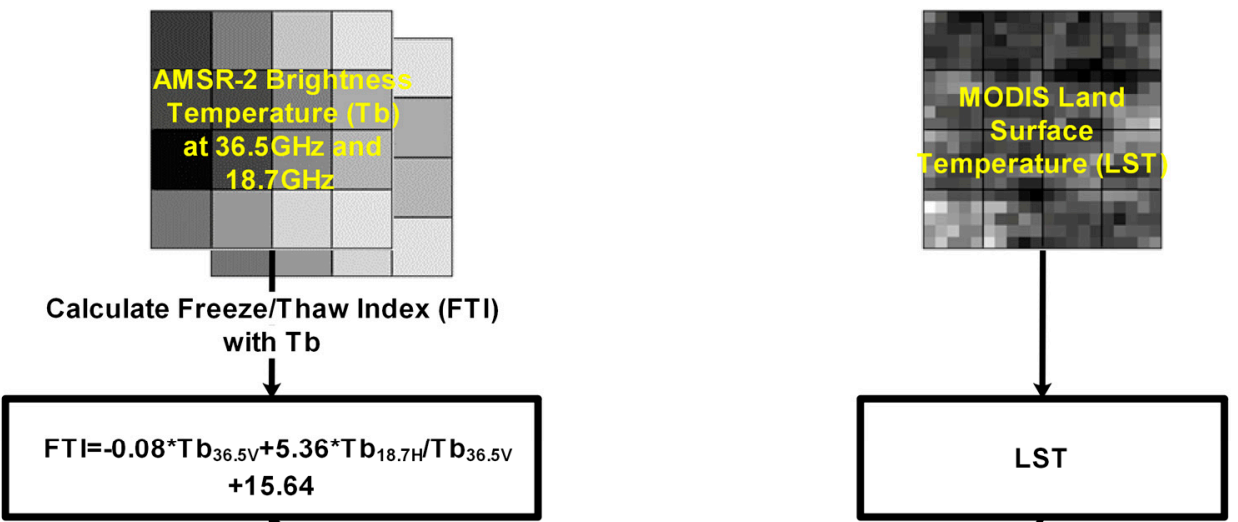
Determine
Freezel

Thaw based

on FTI

calcuated

by AMSR-2

data directly

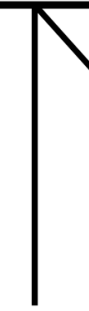

Calibrate location-specific models to estimate

FTI from LST.

$a_{i}, b_{i}$ : coefficients of the model at the ith pixel

Discrimination Algorithm Function (DFA):
Freeze: if $\mathrm{FTI}>0$

Freeze: if $\mathrm{FTI}>0$
Thaw: if $\mathrm{FTI}<0$

$\mathrm{FTl}_{\mathrm{i}}=\mathrm{a}_{\mathrm{i}}{ }^{*} \mathrm{LST}+\mathrm{b}_{\mathrm{i}}$

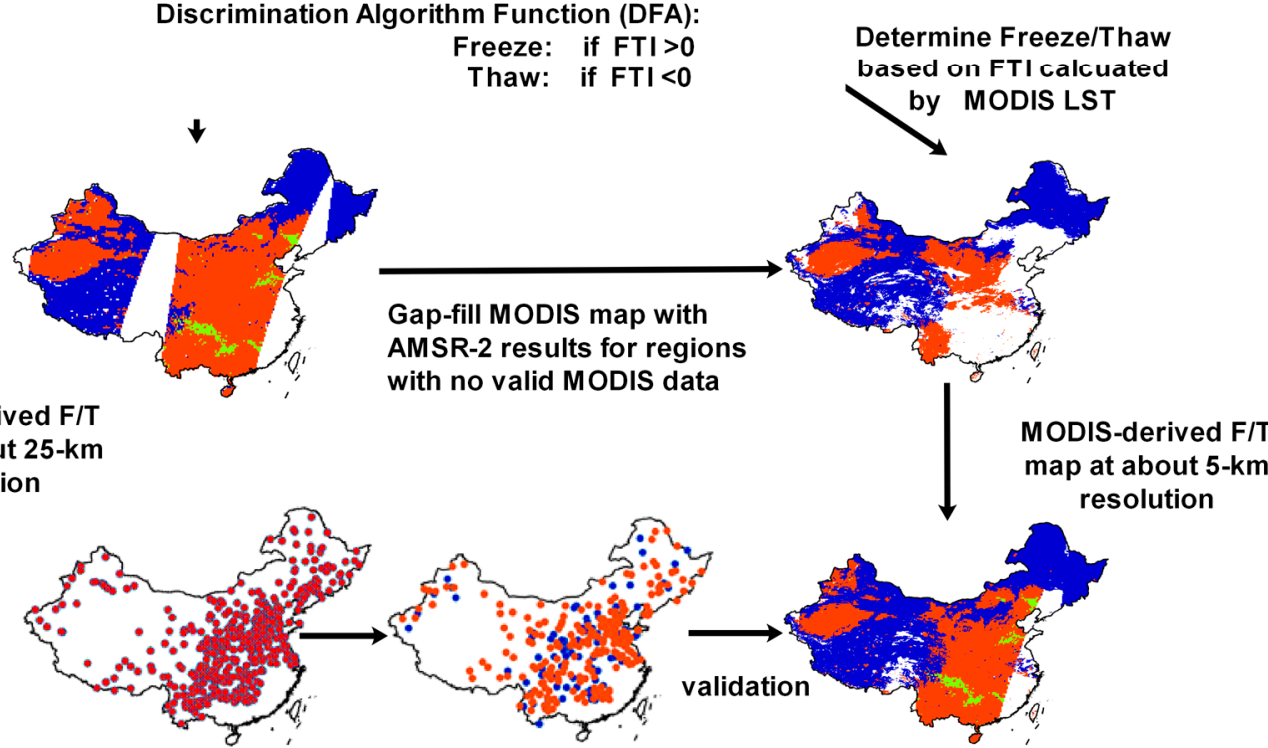

Ground surface temperature measurments at the depth of

$0 \mathrm{~cm}$ from meteorological stations

\section{Ground-thruhing F/T status determined by}

temperature $(T)$ :

Freeze: if $\mathrm{T}>0^{\circ} \mathrm{C}$

Thaw: if $\mathrm{T}<0^{\circ} \mathrm{C}$
Final F/T map at about 5-km resolution

Figure 1. Flowchart of generating high-resolution F/T maps.

A brief introduction of DFA is presented here. DFA was developed based on observations from a truck-mounted multi-frequency microwave radiometer and simulated data from a set of combined models related to vegetation, snow, and soil [13]. The principle of the algorithm is to determine the status of soil in each pixel using two criteria: one is the brightness temperature observed by radiometers at $36.5 \mathrm{GHz}$ in vertical polarization, which is closely related to surface temperature; the other one is called quasi-emissivity and it is the ratio of the brightness temperature in the horizontal polarization at low frequency, such as $6.9,10.65$, and $18.7 \mathrm{GHz}$, to that in vertical polarization at 
36.5 GHz. The quasi-emissivity is related to soil water content. These two criteria are used to construct the discriminant functions based on Fisher linear discriminant analysis [24]:

$$
\begin{gathered}
D_{F}=1.47 * T b_{36.5 \mathrm{~V}}+91.69 * Q e_{18.7 \mathrm{H}}-226.7 \\
D_{T}=1.55 * T b_{36.5 \mathrm{~V}}+86.33 * Q e_{18.7 \mathrm{H}}-242.41 \\
Q e_{18.7 H}=\frac{T b_{18.7 H}}{T b_{36.5 \mathrm{~V}}} \\
F T I=D_{F}-D_{T}
\end{gathered}
$$

where $T b_{36.5 \mathrm{~V}}$ is the vertically-polarized brightness temperature at $36.5 \mathrm{GHz}$ and $Q_{e 18.7 \mathrm{H}}$ is the quasi-emissivity calculated by the low frequency of $18.7 \mathrm{GHz}$. $D_{F}$ and $D_{T}$ are calculated for each pixel and used to classify a pixel as frozen or thawing. If $D_{F}$ is greater than $D_{T}$, the pixel will be classified as frozen; otherwise it will be classified as thawing. The difference of $D_{F}$ and $D_{T}$ is called F/T index (FTI) [17].

\subsubsection{Fusion of F/T Dataset with LST}

The F/T index has shown a linear relationship with LST in previous studies conducted on the Qinghai Tibetan Plateau (QTP). The regression model is in the following form:

$$
F T I=a * L S T+b
$$

where $a$ and $b$ are parameters in the model. The main problem of determining $a$ and $b$ is the unmatched spatial resolutions of LST and FTI.

The approach to matching LST and FTI is by upscaling the spatial resolution of LST to that of FTI. LST is a product of MODIS with 0.05-degree spatial resolution. However, FTI has the same resolution as the passive microwave observations ( 0.25 degree). For each grid of FTI, $5 \times 5$ grids are needed to cover the same area in the LST. If more than 12 of the $5 \times 5$ grids have valid records (determined by quality control data), the average of these valid values will be used to match the value in an FTI grid. Then, a simple linear regression analysis is conducted to determine the relationship based on the matched data pairs between FTI and LST. Once the two parameters $a$ and $b$ are obtained, the linear model can be applied to each pixel of the MODIS LST products to acquire a new FTI, which we called LST-based FTI because it has the same spatial resolution as the LST. For pixels in the LST-based FTI, those with values greater than 0 are classified as frozen, otherwise, they are classified as thawing. If pixels in the LST-based FTI have no values because of gaps or invalid data in the LST, they will be determined using microwave observations alone. Those pixels which are detected as raining will not be determined and just labelled as rain. The new F/T map based on the LST-based FTI is called the high-resolution $\mathrm{F} / \mathrm{T}$ map because its spatial resolution ( 0.05 degree) is higher than F/T maps derived from FTI just using microwave observations ( 0.25 degree). Permanent snow areas are also marked according to the MODIS-International Geosphere-Biosphere Programme (IGBP) land cover classifications.

\subsubsection{Evaluation of the High-Resolution F/T Maps}

A comparison of high-resolution $\mathrm{F} / \mathrm{T}$ maps and $0-\mathrm{cm}$ soil temperatures is divided into two aspects: temporal and spatial agreement. Temporal agreement is calculated daily and it is the ratio of the number of stations whose observations are consistent with the classification result of $\mathrm{F} / \mathrm{T}$ maps and the total number of stations; spatial agreement is calculated by dividing the total observations in a year with the observations that are consistent with the F/T maps for each station. Both the temporal and spatial agreement can be calculated by the equation below:

$$
A=\frac{N_{F F}+N_{T T}}{N_{F F}+N_{F T}+N_{T F}+N_{T T}}
$$


where $N_{F F}$ means the number of pixels where a station is located are classified as frozen, while the ground temperatures are equal, or less than, $0{ }^{\circ} \mathrm{C} ; N_{F T}$ represents the numbers of pixels when they are classified as frozen, while the ground temperatures are above $0{ }^{\circ} \mathrm{C} . N_{T T}$ and $N_{T F}$ follow similar meanings.

\section{Results}

\subsection{Relationship of MODIS LST and Freeze/Thaw Index}

MODIS LST and FTI determined by DFA (Equation (4)) show a high negative correlation in most areas of China (Figure 2). Areas with values below -0.8 take up about $95.4 \%$ and $92.6 \%$ of the domain for observations at 13:30 and 1:30, respectively. The correlation values for both passes are not homogeneously distributed. For ascending and descending time, low correlation less than 0.7 occurs on the QTP, in Central Northeast China and northeast of Xinjiang Province; and most of these three areas also have correlation values around -0.85 . Other parts of the domain have a high negative correlation above 0.9 . Correlation for observations at 1:30 has many more values lower than 0.85. Especially in Southeast of China, in the Hengduan Mountains, correlations are below 0.6. Low correlation values will introduce some inconsistencies between coarse-resolution F/T maps and high-resolution F/T maps, and affect the accuracy of F/T classification. The low correlations may result from many factors, for instance, frequent $\mathrm{F} / \mathrm{T}$ transitions [25], elevation, land cover, as well as the accuracy of observations [26,27].

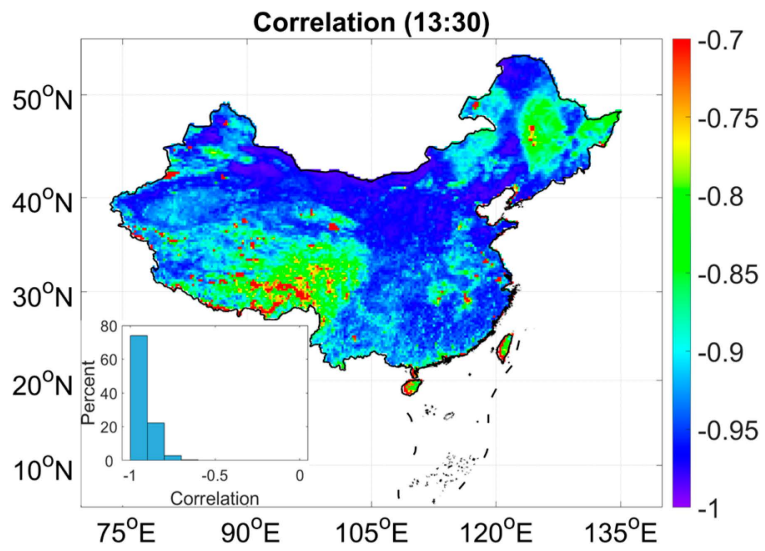

(a)

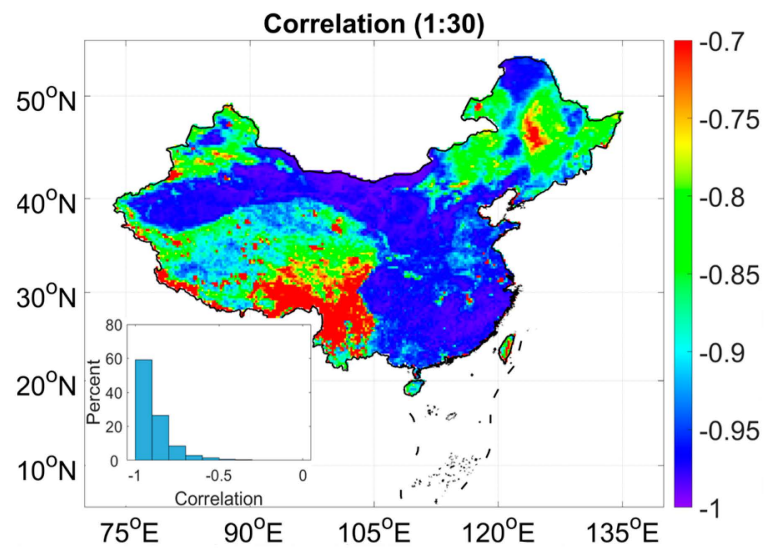

(b)

Figure 2. (a,b) are correlations of the MODIS LST and freeze/thaw index (FTI) for observations at 13:30 and 1:30, respectively.

The parameters "a" and " $b$ " in Equation (5) for each pixel also vary spatially (Figure 3). The low values $(<-0.1)$ of "a", the slope of regression models, exists in the northeast and parts of Xinjiang province in China. In southeast and central parts, the slope is above -0.1 . About $70 \%$ of the pixels have a value between -0.1 and -0.06 for " $a$ " observations at both 13:30 and 1:30. However, observations at 1:30 have more low values than that at 13:30. The slope of a model, as well as the intercept, are adjustments made to match the emissivity of MODIS in thermal bands to that of AMSR2 in the 36.5 GHz band (Equations (4) and (5)). These two parameters depend on how many observations are used and at what time observations are acquired. Here, observations of only two years (2013 and 2014) were used to fit linear models for each pixel. Taking a pixel $\left(31^{\circ} \mathrm{N}, 91^{\circ} \mathrm{E}\right)$ as an example, 455 effective data pairs are selected for 13:30, while only 350 data pairs are used for observations at 1:30 to fit a model. In addition, the pattern of data pairs is not the same (subplots in Figure 3a,b). This pixel experiences both freezing and thawing at 13:30 during the two years, so some values of FTI are greater 
than 0 and some are less than 0 . However, for observations at 1:30, the status of this pixel is frozen most of the time, so many values of FTI are less than 0 .

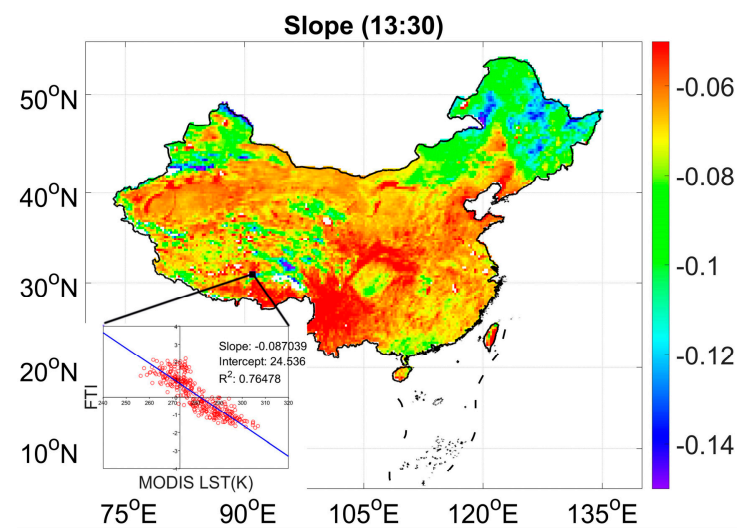

(a)

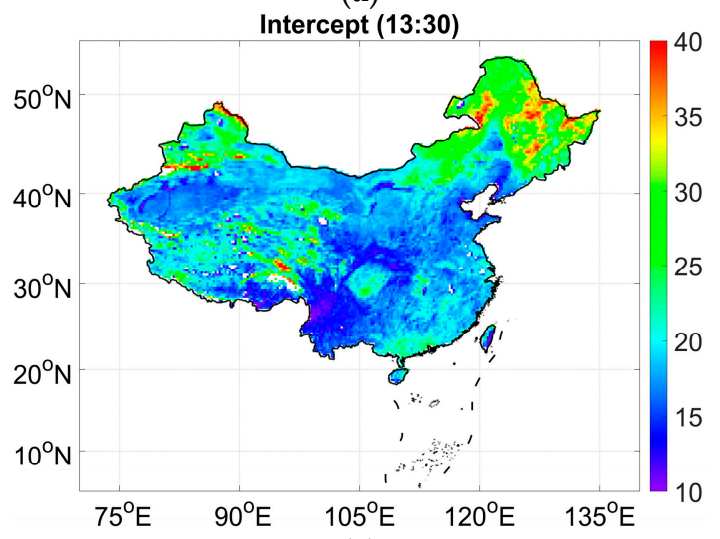

(c)

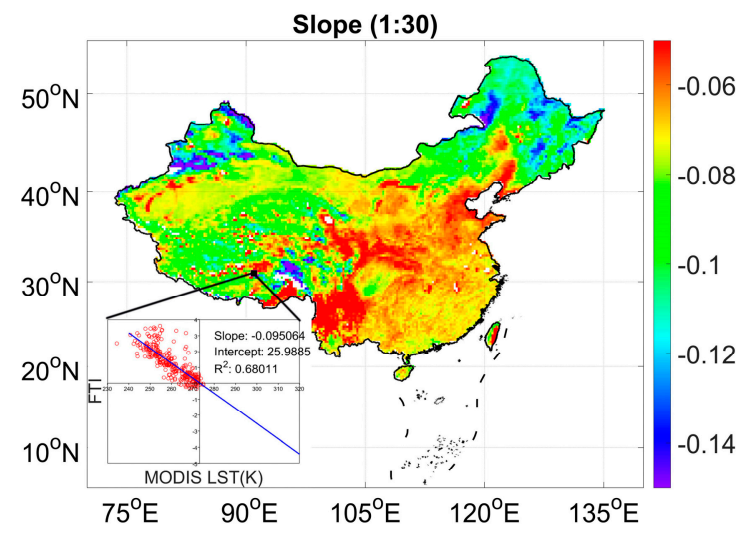

(b)

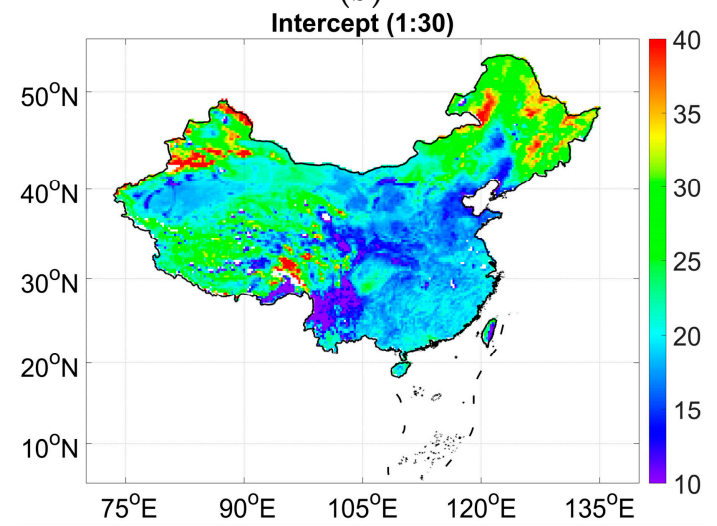

(d)

Figure 3. Spatial distribution of parameters " $a$ " and " $b$ " in regression models for observations at 13:30 and 1:30, respectively. $(\mathbf{a}, \mathbf{b})$ are for " $a$ "; $(\mathbf{c}, \mathbf{d})$ are for " $b$ ".

\subsection{Daily High-Resolution F/T Map of China}

Daily high-resolution F/T maps are a combination of AMSR2-based and MODIS LST-based F/T maps (Figure 1). AMSR2-based F/T maps are determined by FTI, which is calculated by applying DFA to AMSR2 observations directly. Such a map has a coarse resolution of 0.25 degree, so we use "coarse-resolution" here to describe F/T maps based on passive microwave observations. MODIS LST-based FTI is calculated by applying Equation (5) to daily MODIS LST maps. Once the LST-based FTI was acquired, discrimination analysis is applied to each pixel to acquire high-resolution F/T maps. Such an F/T map has a resolution of 0.05 degree. Although 0.05 degrees is not actually high, we use "high-resolution" to represent the F/T map generated by the MODIS LST compared with that by passive microwave observations. The high-resolution F/T maps cover all land surfaces in China where F/T transitions probably occur and consist of five values, namely: frozen (0), thawing (1), no data (2), rain (3), and permanent snow (15). The rain information comes from coarse-resolution F/T maps. Permanent snow areas are labeled as 15 because they are determined by the MODIS-IGBP land cover classifications.

Coarse-resolution F/T maps not only provide information about precipitation, but also act as supplements where gaps or invalid data appear in MODIS observations. The gaps in high-resolution maps means observations are invalid for both MODIS and AMSR2, so they are smaller than that from either sensor. Since parts of gaps are filled, daily high-resolution F/T maps can provide much more information in a finer resolution than coarse-resolution F/T maps. As the high-resolution F/T maps 
are combined by information from both high-resolution and coarse-resolution, we estimated how much information from MODIS (actual high resolution) can be used for each day. Figure 4a shows that an average of $58.5 \%$ and $65.4 \%$ of the whole area can have actual high-resolution information at ascending and descending times, respectively. Moreover, the frequency of each pixel with actual high resolution in the year of 2013 varies spatially (Figure 4b,c). Areas in Western China have more days of high-resolution observations. Some areas, such as Sichuan, Guizhou, and Guangxi Provinces have fewer days of high-resolution observations. This pattern is much more obvious at the descending time.

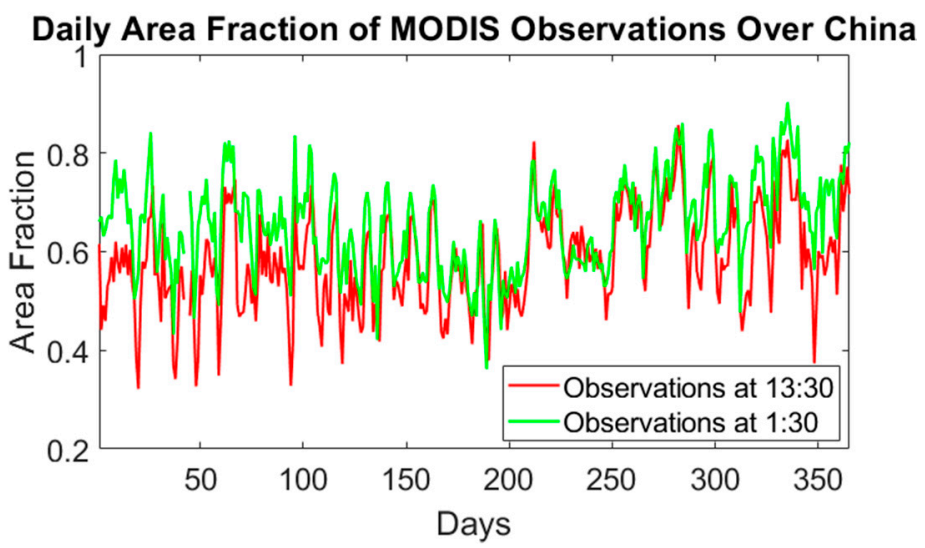

(a)

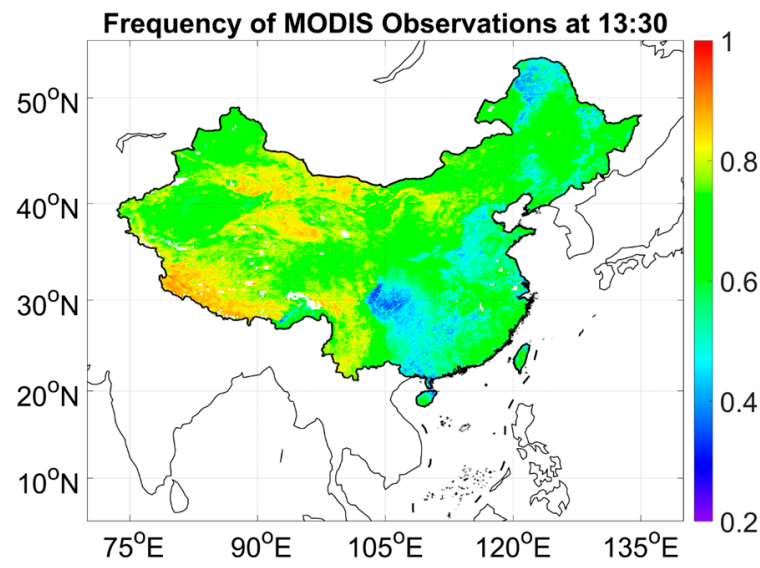

(b)

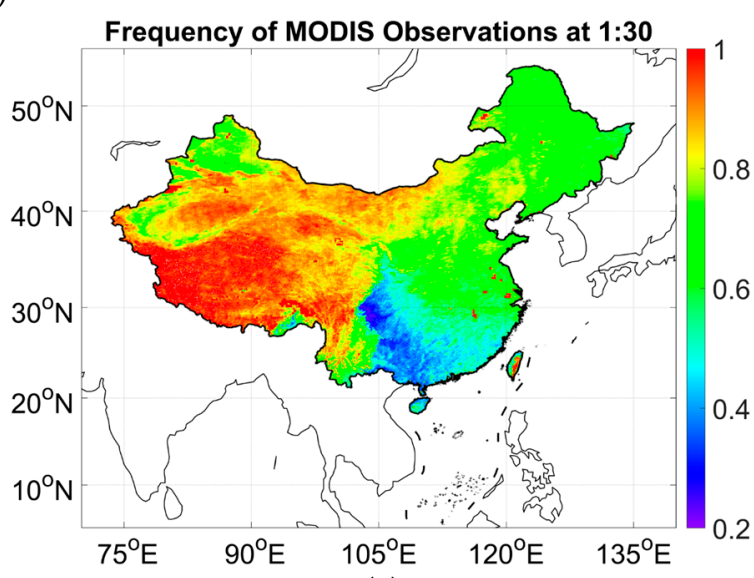

(c)

Figure 4. Coverage of MODIS observations over China in 2013 (a) and frequency of valid MODIS observations for each pixel at 13:30 (b) and 1:30 (c) in 2013.

\subsection{Agreement between the Ground Temperature and High-Resolution F/T Maps}

Agreements between high-resolution F/T maps and ground temperatures are calculated temporally and spatially. The temporal agreement was calculated separately at ascending (Figure 5a) and descending times (Figure 5b). Overall temporal agreements for ascending and descending times are $95.37 \%$ and $86.6 \%$, respectively. The high temporal agreements come from thaw status. $\mathrm{N}_{\mathrm{TT}}$, the number of stations where the ground temperature is above 0 degrees and the pixels where stations are located are classified as thaw, take up more than $90 \%$ of the four components $\left(\mathrm{N}_{\mathrm{TT}}, \mathrm{N}_{\mathrm{TF}}, \mathrm{N}_{\mathrm{FF}}, \mathrm{N}_{\mathrm{FT}}\right)$ through the whole year, which means that many days in 2013 are thawing at around 13:30. The overall low agreement at 13:30 appears in late fall, winter, and early spring (the average accuracy is $93 \%$ in winter and $91.01 \%$ in spring) during which the F/T transitions are occurring in most areas of the north of the Yangzi River in China. Low agreement in similar periods also appears for observations at $1: 30(82.1 \%$ in spring and $82.5 \%$ in winter $)$, but the pattern of time-series agreement at $1: 30$ is slightly different from that at 13:30. Thawing components detected by both stations and satellite $\left(\mathrm{N}_{\mathrm{TT}}\right)$ 
are lower than frozen components $\left(\mathrm{N}_{\mathrm{FF}}\right)$ in winter and early spring. This is reasonable because the descending time is around 1:30 a.m., when the minimum temperature of a day is usually observed.

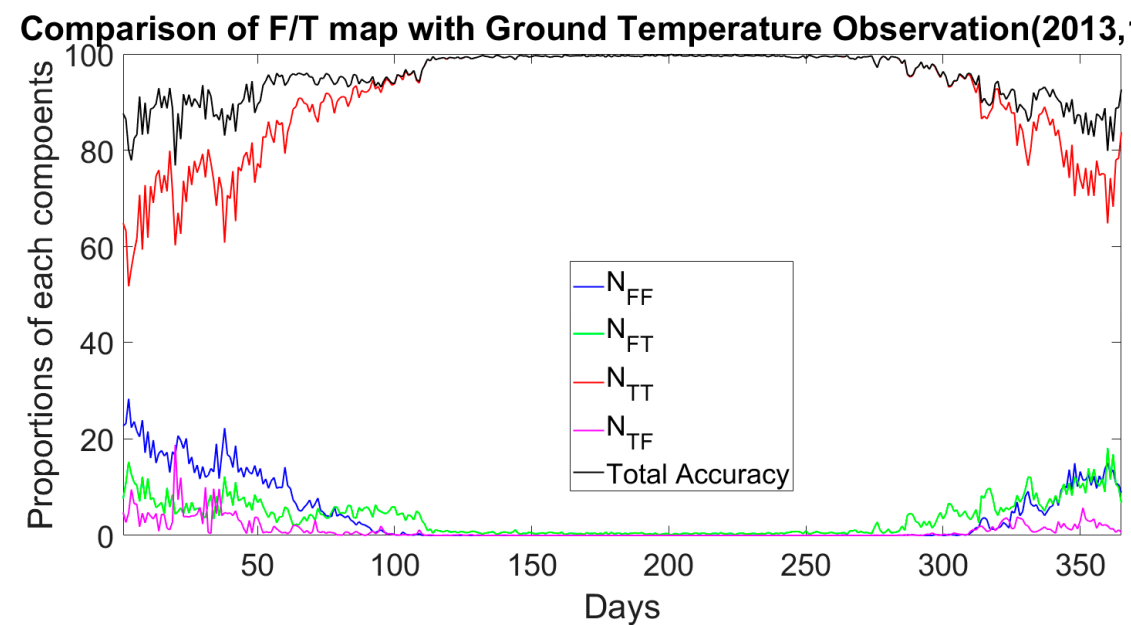

(a)

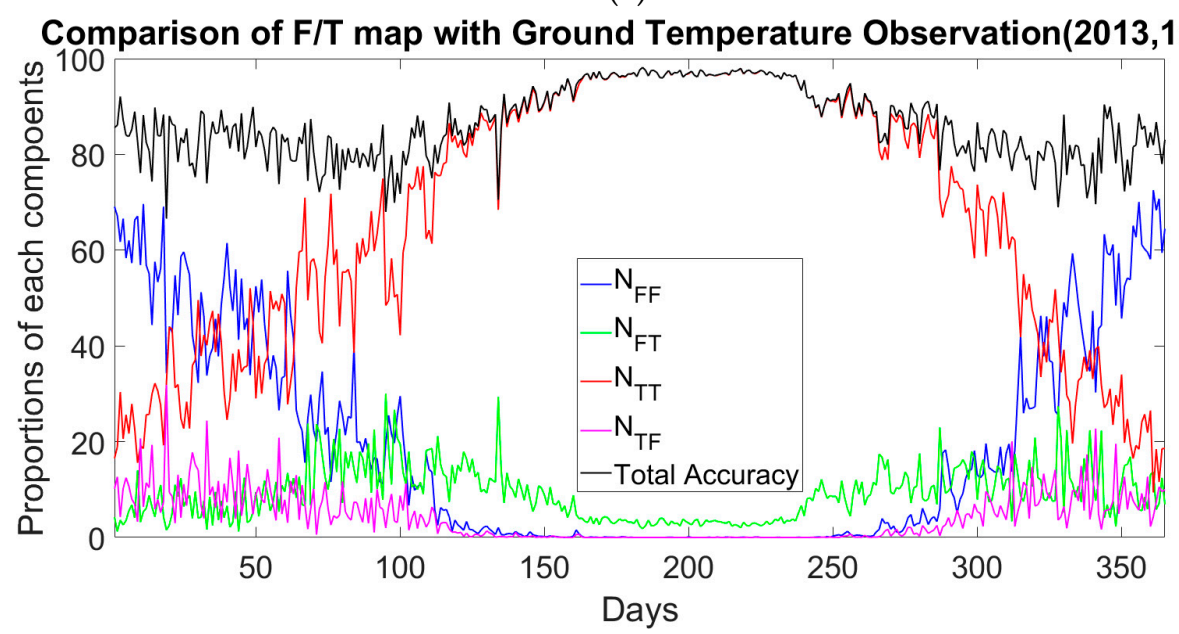

(b)

Figure 5. Temporal agreement between in situ measurement and F/T maps for observations at 13:30 (a) and 1:30 (b).

Figure 6 shows that high-resolution F/T maps have high agreement with in situ ground temperature (overall agreement: $91.25 \%$ ). The agreement is not distributed homogeneously across China, but the pattern is similar to that of correlation mentioned in Section 3.1. Areas with low agreement below 80\% are mainly located in Western and Northeast China, the Yangzi River Delta, and other areas near the sea. The reasons for low agreement are various. In Western China, the meteorological stations are distributed sparsely, and not enough measurements may account for the low agreement. In addition, both the northwest and northeast are cold and arid zones, such as the Qinghai-Tibetan Plateau, Xinjiang, Gansu, Heilongjiang, Jilin, and Liaoning Province. These areas experience low mean annual temperature and large F/T dynamics. Other areas, for example, the Yangzi River Delta, Liaoning, and Shandong Peninsula, are near rivers or the sea. Locations near water may be an important factor leading to low accuracy [28]. 


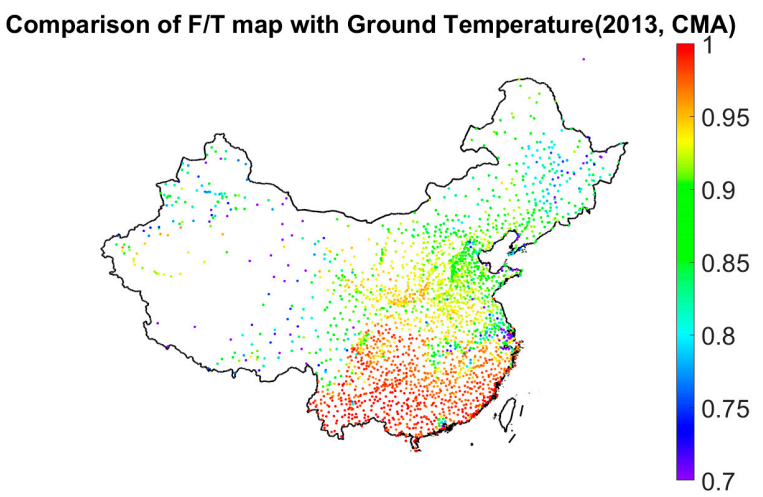

Figure 6. Accuracy assessment of F/T maps at individual meteorological stations in China.

\section{Discussion}

\subsection{High-Resolution F/T Maps}

Fusion of passive microwave and thermal observations to generate high-resolution $\mathrm{F} / \mathrm{T}$ maps is proved possible. However, fused F/T maps depend greatly on DFA, an algorithm derived for observations of AMSR-E. Although AMSR-E and AMSR2 have been reported to have slight differences [29,30], eliminating the difference is still necessary through inter-calibration before applying the same algorithm (e.g., DFA) to observations of these two sensors [31]. The data of AMSR2 used in this study have been calibrated with AMSR-E without many details being obtained [23]. The high-resolution F/T maps also depend significantly on thermal observations, especially the spatial resolution. Theoretically, the higher the resolution of thermal observations, the finer the fused $\mathrm{F} / \mathrm{T}$ maps will be. For example, F/T maps with 1-km resolution are also possible to acquire if the LST products with 1-km resolution are used.

Increasing the resolution of land surface parameters (LST, albedo, soil moisture, etc.) has been of considerable interest for the land surface community as the improved knowledge of land surface parameters can enhance a wide range of applications and scientific studies, such as the community land model [32-36]. F/T maps derived by DFA or other algorithms [12] based on passive microwave observations usually have a spatial resolution of 0.25 degree. Such a coarse resolution limits the application of $\mathrm{F} / \mathrm{T}$ data in climate or hydrological models that consider land surface heterogeneity [14]. Finer resolution of $\mathrm{F} / \mathrm{T}$ maps are needed to meet the current scientific research requirements [15]. High-resolution F/T status detections by radar or scatterometer are considerably mature [37], but F/T maps with high resolution in large scales and short revisit times are still unavailable. The fusion of microwave observation-based $\mathrm{F} / \mathrm{T}$ maps and thermal observations has been proved promising on QTP areas [17]. The similar approach has been tested in China and performs well. Theoretically, the study areas can be extended to the globe, and a long-time series F/T record can also be built using observations within the life span of AMSR2 and MODIS. However, impacts on F/T transitions from factors, for instance, snow, vegetation, topography, etc., are challenges faced by remote sensing observations [38]. The influence of land cover is weakness of the approach proposed here. More work is needed to tackle the influence the F/T dynamics caused by snow, vegetation, elevation, etc., at a finer scale.

\subsection{Strengths and Weaknesses of Fused F/T Maps}

The fused F/T maps are superior to those derived directly based on passive microwave or thermal observations alone in at least two aspects: more information and finer spatial resolution (at least part of the map actually has high resolution). Compared with F/T maps derived directly from passive microwave observations, much finer information was introduced to the F/T maps, which is more promising for future use in many regional studies [33] or land models [14,32]. Compared with the F/T status determined by the MODIS LST threshold (we use $0{ }^{\circ} \mathrm{C}$ as a cutoff: frozen if a pixel lower or equal 
0 , otherwise thawing), fused maps provide more effective observations and without losing accuracy. Table 2 is a case study using several randomly-selected meteorological stations for different land cover types. MODIS LST has many observations of barren areas, such as Qinghai Province (Figure $4 b, c$ ), with high agreement with station measurements, but it has fewer observations in areas with a large amount of vegetation and high elevation (e.g., station 56649). For fused F/T maps, both accuracy and effective observations are very stable in different kinds of areas and land cover types.

Table 2. Comparision of F/T status determined by the MODIS LST threshod $\left(0^{\circ} \mathrm{C}\right)$ and fused F/T maps.

\begin{tabular}{|c|c|c|c|c|c|c|c|}
\hline Station ID & Land Cover & $\begin{array}{l}\text { Latitude } \\
\left({ }^{\circ} \mathrm{N}\right)\end{array}$ & $\begin{array}{l}\text { Lontitude } \\
\left({ }^{\circ} \mathrm{E}\right)\end{array}$ & Accuracy_MOD & $\begin{array}{c}\text { Effective } \\
\text { Observations (MOD) }\end{array}$ & Accuracy_F & $\begin{array}{c}\text { Effective } \\
\text { Observations (F) }\end{array}$ \\
\hline 51777 & Barren areas & 39.033 & 88.167 & $93.27 \%$ & 271 & $89.63 \%$ & 363 \\
\hline 56067 & Gras land (1) ${ }^{1}$ & 33.433 & 101.48 & $80.76 \%$ & 260 & $86.96 \%$ & 363 \\
\hline 54012 & Grassland (2) $^{1}$ & 44.567 & 117.63 & $89.91 \%$ & 238 & $87.68 \%$ & 363 \\
\hline 50434 & Forest (1) ${ }^{1}$ & 50.483 & 121.68 & $93.47 \%$ & 230 & $90.51 \%$ & 363 \\
\hline 50349 & Forest (2) ${ }^{1}$ & 51.667 & 124.4 & $90.91 \%$ & 231 & $90.33 \%$ & 363 \\
\hline 56649 & Forest (3) ${ }^{1}$ & 21.6 & 99.967 & $77.38 \%$ & 252 & $89.80 \%$ & 363 \\
\hline 58011 & Cropland & 34.8 & 116.07 & $86.34 \%$ & 183 & $90.89 \%$ & 363 \\
\hline 57343 & Deciduous Forest & 31.9 & 109.53 & $86.07 \%$ & 201 & $93.36 \%$ & 363 \\
\hline 59205 & Savanna & 23.65 & 105.63 & $97.48 \%$ & 119 & $99.42 \%$ & 363 \\
\hline
\end{tabular}

1: Grassland (1) is located on the QTP; Grassland (2): Inner Monngolia; Forest (1): Daxinganling Forest; Forest (2):

Xiaoxinganling Forest; Forest (3): the Hengduan Mountains.

The fused F/T maps also have some limitations because they depended on the match of MODIS LST with microwave observations. The correlation of and coefficents (" $a$ " and " $b$ " in Equation (5)) of the linear regression model will be influenced by many factors, for instance, land cover types, vegetaion, elevation, seasonality, etc. Figure 7 shows how correlation varies with different elevations between the MODIS LST and FTI derived by microwave observations. For both observations at 13:30 and 1:30, the rise in elevation is companied with the decrease in correlation, and correlation remains high and stable when elevations are below $2000 \mathrm{~m}$. We also investigated how correlations vary with Normalized Difference Vegetation Index (NDVI) at different sites with different land cover (Figure 8). NDVI also shows a negative influence on correlation, especially for observations at 1:30 with extreme high NDVI values. We guess that MODIS measures the temperature of vegetation while AMSR2 can penetrate vegetation to measure near surface temperature of the ground in forest areas. Another limitation for the regression models is that parameters " $a$ " and " $b$ " for each pixel are fixed at different seasons through the year. However, as they are adjusted to approximate the emissivity of MODIS at thermal bands to AMSR2 in the $36.5 \mathrm{GHz}$ band, they may vary at different times of the year, especially as land cover changes with time, for example, vegetation (Figure A1) and snow cover. This problem is not solved in this study, but the analysis provides directions on how to improve our regression model; for example, we can let "a" and "b" vary with NDVI.

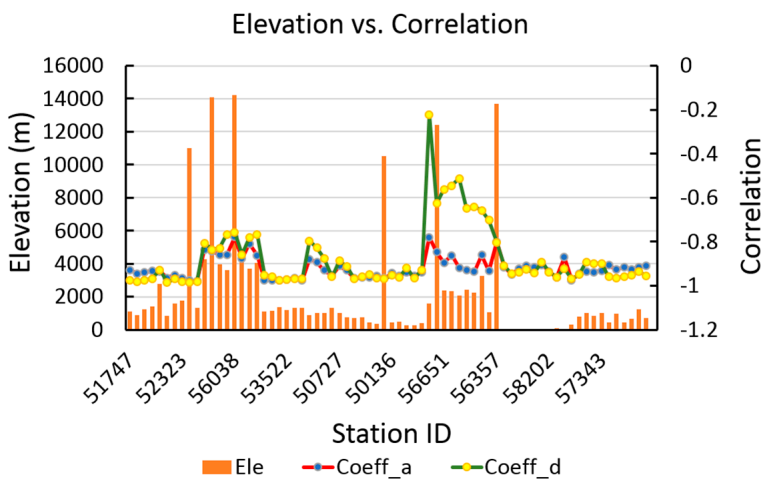

Figure 7. Correlation of the MODIS LST and FTI derived by microwave observations from 70 randomly-selected stations at different elevations. Ele is the elevation of the stations; Coeff_a is the correaltion at 13:30; Coeff_d is the correlation at 1:30. 


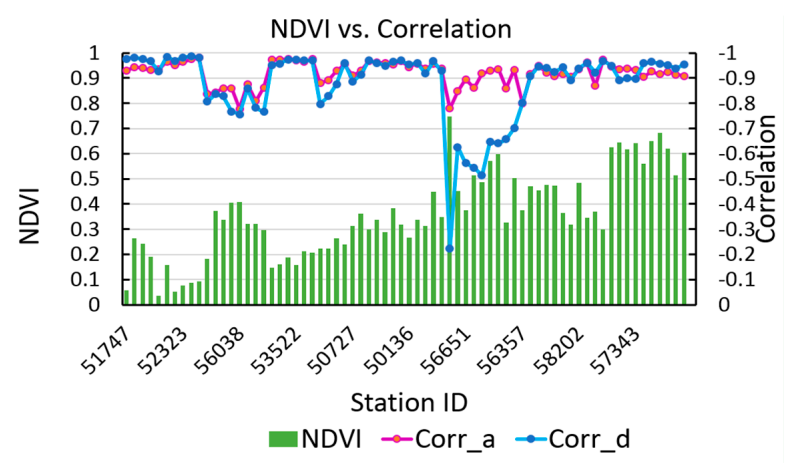

Figure 8. Correlation of the MODIS LST and FTI derived by microwave observations from 70 randomly-selected stations with different annual average NDVI. Corr_a is the correaltion at 13:30; Corr_d is the correlation at 1:30.

\subsection{Accuracy Estimate by Ground Temperature}

The accuracy estimation shows that the high-resolution F/T maps have high agreement with ground temperature. However, the main concern is, and has been argued for a long time, that the $0-\mathrm{cm}$ temperature on the ground is explicit to define the $\mathrm{F} / \mathrm{T}$ state of the land surface. The ground may be thawing when the $0-\mathrm{cm}$ temperature is equal, or less than, $0{ }^{\circ} \mathrm{C}$, and factors, such as wind or land cover (snow, vegetation, etc.) may also lead to the thaw status. However, until now, there has been no better criteria to define the absolute real boundary of the temperature when the ground is frozen or thawing. Compared with other choices, for example, air temperature [4] and soil temperatures at different depths or from models [16], 0-cm ground temperature may be a better choice because it reflects the surface state of the ground. This "surface " is probably what remote sensing is detecting.

\section{Conclusions}

$\mathrm{F} / \mathrm{T}$ transitions of near surface soil have been investigated by microwave remote sensing, but most of them are in a coarse resolution or in a small area. Fine-resolution F/T status data records at a large scale and short revisit time are still unavailable presently. Thus, a new approach to detecting F/T status was tested and evaluated in a large area (China) in this study. This approach takes advantage of passive microwave and thermal remote sensing observations to map F/T status in a high spatial resolution (0.05 degree). This high-resolution F/T map is a fusion of the coarse-resolution F/T maps from AMSR2 and MODIS LST-based FTI. Then the high-resolution F/T map was validated using 0-cm ground temperatures across China. The following conclusions can be drawn from this paper:

(1) The determination function algorithm (DFA) provides an interface between passive microwave and thermal observations. Their relationship can be described using a linear regression model through the parameter FTI.

(2) The regression model applied to MODIS temperature can provide high-resolution F/T maps which are promising to fill the gap when no other high-resolution F/T maps can cover the globe or a large area.

(3) The high-resolution F/T maps show high agreement with 0 -cm ground temperatures with spatial agreement above $90 \%$ and temporal agreement around $95.37 \%$ and $86.62 \%$ for ascending and descending passes, respectively. The high agreement enhances the reliability of the derived high-resolution F/T maps which can be used for further research in Earth sciences.

High-resolution F/T maps by fusing multi-source remote sensing data have several advantages: providing much more $\mathrm{F} / \mathrm{T}$ information than those relying purely on passive microwave remote sensing; and having fewer gaps in the image than that from either AMSR2 or MODIS. Both microwave and thermal sensors have their own advantages, fused F/T maps reach a balance between temporal and 
spatial resolution of remote sensing observations. Although the approach used here is proved to be promising, it still has many limitations because of the influence of topography, seasonality, vegetation cover, etc. Future studies of incorporating NDIV, emissivity, and flexible coefficients varying with time are highly recommended to improve the approach.

Acknowledgments: This study was jointly supported by the National Key Basic Research Program of China (2015CB953701), the National Natural Science Foundation of China (41671355), the Chinese Academy of Sciences "Light of West China" Program, and the Youth Innovation Promotion Association (no. 2016061). K.Z. acknowledges the supports from the Open Research Fund from the State Key Laboratory of Digital Earth Science, Institute of Remote Sensing and Digital Earth, Chinese Academy of Sciences(OFSLRSS201604) and a Microsoft Azure Research Award (CRM:0518513). All data of AMSR-E and MODIS are obtained from the National Snow and Ice Data Center (NSIDC). The ground temperature data are from the China Meteorological Administration.

Author Contributions: T.H., T.Z., J.S., and K.Z. contributed to intellectual design and initial drafting. T.H. compiled and processed data. T.H., T.Z., S.W. and K.Z. contributed to data analysis and interpretation. D.L. and H.Q. assisted with graphing and the manuscript revision. All the authors contributed to the writing of the final draft.

Conflicts of Interest: The authors declare no conflict of interest.

\section{Appendix A}

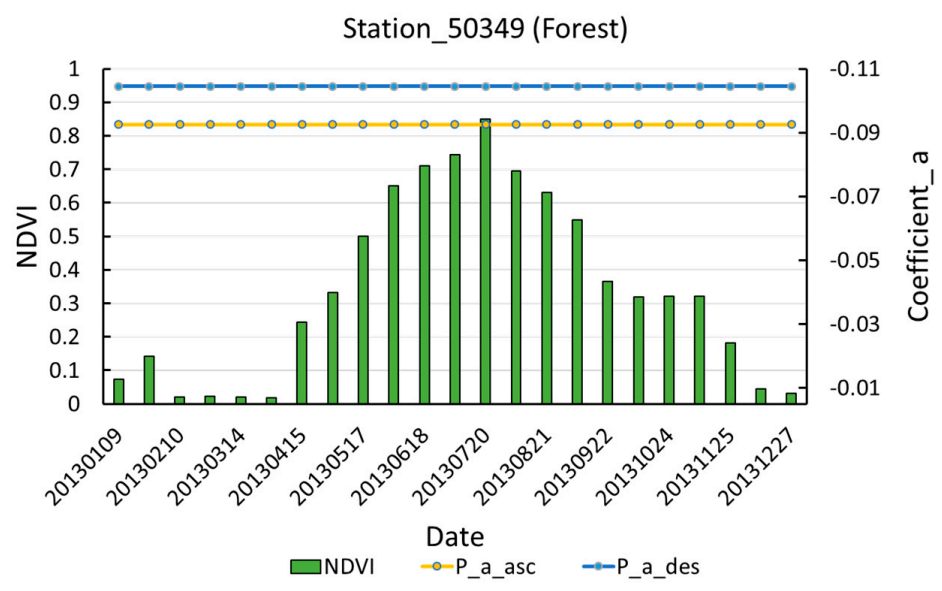

(a)

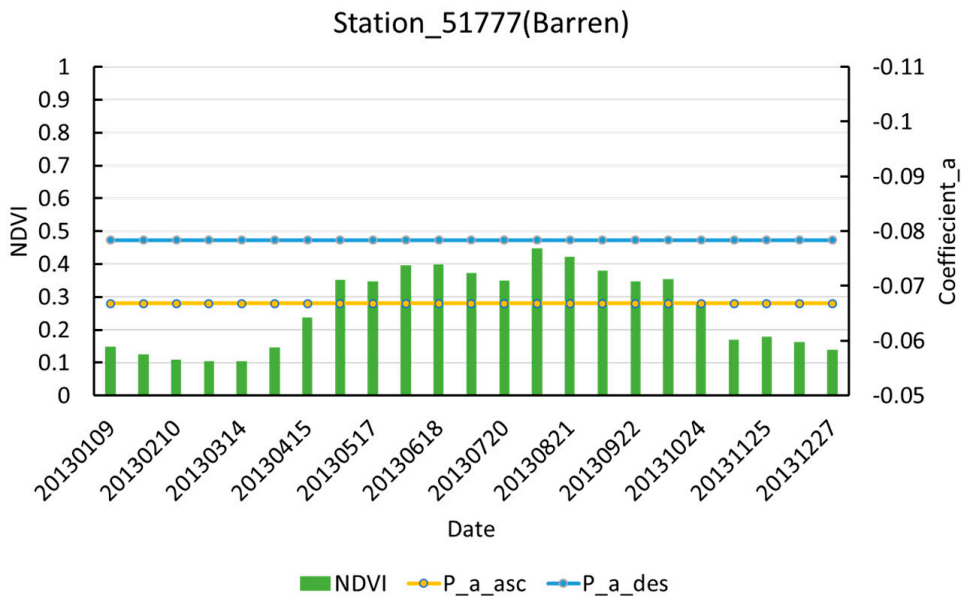

(b)

Figure A1. Cont. 


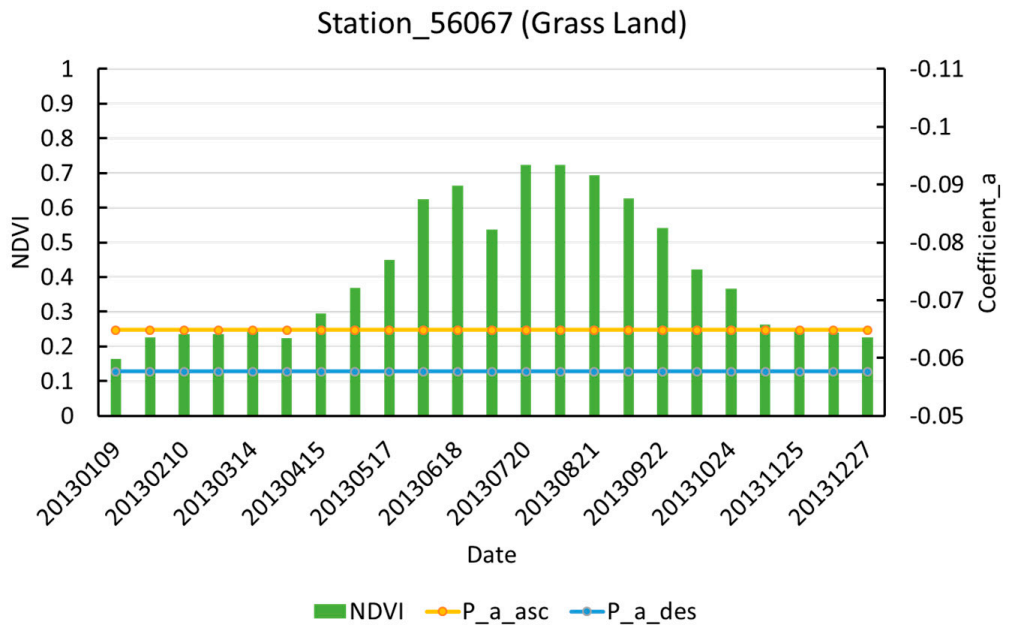

(c)

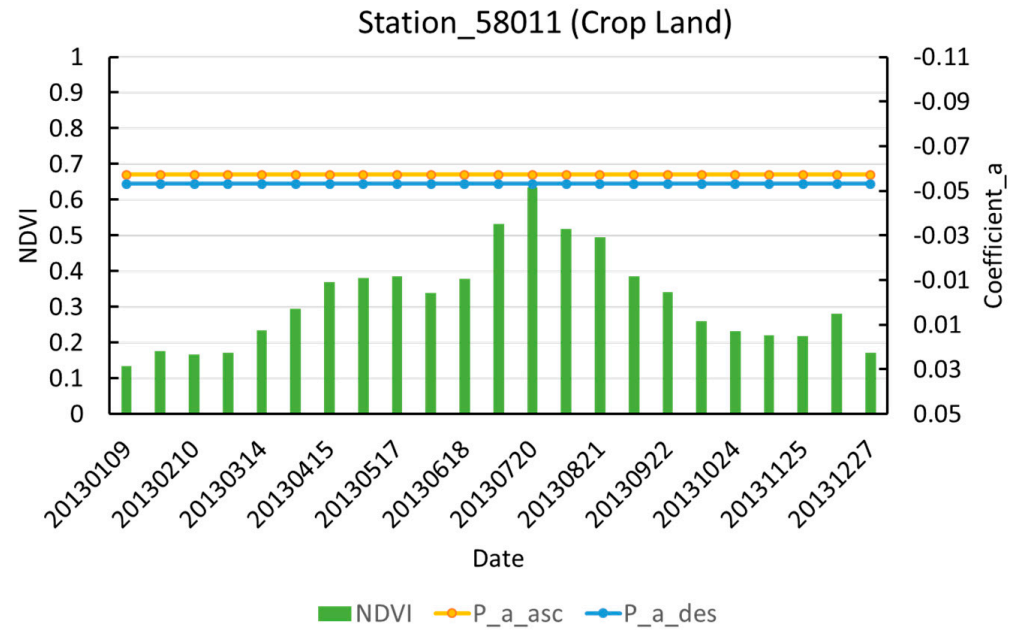

(d)

Figure A1. Parameter "a" and NDVI on forest (a), barren (b), grass land (c) and crop land (d). P_a_asc and P_a_des are for observations at 13:30 and 1:30, respectively.

\section{References}

1. Zhang, T.; Barry, R.; Knowles, K.; Ling, F.; Armstrong, R. Distribution of seasonally and perennially frozen ground in the Northern Hemisphere. In Proceedings of the 8th International Conference on Permafrost, Zurich, Switzerland, 21-25 July 2003; AA Balkema Publishers: Amsterdam, The Netherlands, 2003; pp. 1289-1294.

2. McDonald, K.C.; Kimball, J.S. Estimation of surface freeze-thaw states using microwave sensors. In Encyclopedia of Hydrological Sciences; John Wiley \& Sons, Ltd.: Hoboken, NJ, USA, 2005.

3. Intergovernmental Panel on Climate Change (IPCC). Climate Change 2013: The Physical Science Basis. Contribution of Working Group I to the Fifth Assessment Report of the Intergovernmental Panel on Climate Change; Stocker, T.F., Qin, D., Plattner, G.-K., Tignor, M., Allen, S.K., Boschung, J., Nauels, A., Xia, Y., Bex, V., Midgley, P.M., Eds.; Cambridge University Press: Cambridge, UK; New York, NY, USA, 2013; p. 1535.

4. Kim, Y.; Kimball, J.S.; McDonald, K.C.; Glassy, J. Developing a global data record of daily landscape freeze/thaw status using satellite passive microwave remote sensing. IEEE Trans. Geosci. Remote Sens. 2011, 49, 949-960. [CrossRef] 
5. Kimball, J.S.; McDonald, K.C.; Keyser, A.R.; Frolking, S.; Running, S.W. Application of the NASA scatterometer (NSCAT) for determining the daily frozen and nonfrozen landscape of Alaska. Remote Sens. Environ. 2001, 75, 113-126. [CrossRef]

6. Wagner-Riddle, C.; Congreves, K.A.; Abalos, D.; Berg, A.A.; Brown, S.E.; Ambadan, J.T.; Gao, X.; Tenuta, M. Globally important nitrous oxide emissions from croplands induced by freeze-thaw cycles. Nat. Geosci. 2017, 10, 279-283. [CrossRef]

7. Global Climate Observing System. The Global Observing System for Climate: Implementation Needs; Global Climate Observing System: Guayaquil, Ecuador, 2016.

8. Entekhabi, D.; Njoku, E.G.; O’Neill, P.E.; Kellogg, K.H.; Crow, W.T.; Edelstein, W.N.; Entin, J.K.; Goodman, S.D.; Jackson, T.J.; Johnson, J. The soil moisture active passive (SMAP) mission. Proc. IEEE 2010, 98, 704-716. [CrossRef]

9. Zhang, T.; Armstrong, R. Soil freeze/thaw cycles over snow-free land detected by passive microwave remote sensing. Geophys. Res. Lett. 2001, 28, 763-766. [CrossRef]

10. Ulaby, F.T.; Moore, R.K.; Fung, A.K. Microwave Remote Sensing Active and Passive-Volume III: From Theory to Applications; Artech House, Inc.: Norwood, MA, USA, 1986.

11. Jin, R.; Li, X.; Che, T. A decision tree algorithm for surface soil freeze/thaw classification over China using SSM/I brightness temperature. Remote Sens. Environ. 2009, 113, 2651-2660. [CrossRef]

12. Kim, Y.; Kimball, J.S.; Glassy, J.; Du, J. An extended global earth system data record on daily landscape freeze-thaw status determined from satellite passive microwave remote sensing. Earth Syst. Sci. Data 2017, 9, 133-147. [CrossRef]

13. Zhao, T.; Zhang, L.; Jiang, L.; Zhao, S.; Chai, L.; Jin, R. A new soil freeze/thaw discriminant algorithm using AMSR-E passive microwave imagery. Hydrol. Process. 2011, 25, 1704-1716. [CrossRef]

14. Chakrabarti, S.; Bongiovanni, T.; Judge, J.; Nagarajan, K.; Principe, J.C. Downscaling satellite-based soil moisture in heterogeneous regions using high-resolution remote sensing products and information theory: A synthetic study. IEEE Trans. Geosci. Remote Sens. 2015, 53, 85-101. [CrossRef]

15. Shi, J.; Dong, X.; Zhao, T.; Du, J.; Jiang, L.; Du, Y.; Liu, H.; Wang, Z.; Ji, D.; Xiong, C. WCOM: The science scenario and objectives of a global water cycle observation mission. In Proceedings of the 2014 IEEE International Geoscience and Remote Sensing Symposium (IGARSS), Quebec City, QC, Canada, 13-18 July 2014; pp. 3646-3649.

16. Zwieback, S.; Paulik, C.; Wagner, W. Frozen soil detection based on advanced scatterometer observations and air temperature data as part of soil moisture retrieval. Remote Sens. 2015, 7, 3206-3231. [CrossRef]

17. Zhao, T.; Shi, J.; Hu, T.; Zhao, L.; Zou, D.; Wang, T.; Ji, D.; Li, R.; Wang, P. Estimation of high-resolution near-surface freeze/thaw state by the integration of microwave and thermal infrared remote sensing data on the Tibetan Plateau. In Earth and Space Science; Wiley: Hoboken, NJ, USA, 2017.

18. Wentz, F.; Meissner, T.; Gentemann, C.; Hilburn, K.; Scott, J. Remote Sensing Systems GCOM-W1 AMSR2 Daily Environmental Suite on 0.25 Deg Grid Version 7.2; Remote Sensing Systems: Santa Rosa, CA, USA, 2014.

19. Gcom-W1 Data Providing Service. Available online: https://gcom-w1.jaxa.jp/auth.html (accessed on 23 Octorber 2016).

20. Wan, Z. New refinements and validation of the modis land-surface temperature/emissivity products. Remote Sens. Environ. 2008, 112, 59-74. [CrossRef]

21. China Meteorological Data Service Center (CMDC). Available online: http://data.cma.cn/en/?r=data/ detail\&dataCode=A.0029.0004 (accessed on 12 December 2016).

22. Chai, L.N.; Zhang, L.X.; Zhang, Y.Y.; Hao, Z.G.; Jiang, L.M.; Zhao, S.J. Comparison of the classification accuracy of three soil freeze-thaw discrimination algorithms in China using SSMIS and AMSR-E passive microwave imagery. Int. Remote. Sens. 2014, 35, 7631-7649. [CrossRef]

23. Hu, T.; Zhao, T.; Shi, J.; Wang, T.; Ji, D.; Al Bitar, A.; Peng, B.; Cui, Y. Development and analysis of a continuous record of global near-surface soil freeze/thaw patterns from AMSR-E and AMSR2 data. Cryosphere Discuss. 2016. [CrossRef]

24. Welling, M. Fisher Linear Discriminant Analysis; Department of Computer Science, University of Toronto: Toronto, ON, Canada, 2005; Volume 3.

25. Ran, Y.; Li, X.; Cheng, G.; Zhang, T.; Wu, Q.; Jin, H.; Jin, R. Distribution of permafrost in China: An overview of existing permafrost maps. Permafr. Periglac. Process. 2012, 23, 322-333. [CrossRef] 
26. Shi, Q.; Liang, S. Characterizing the surface radiation budget over the Tibetan Plateau with ground-measured, reanalysis, and remote sensing data sets: 1. Methodology. J. Geophys. Res. Atmos. 2013, 118, 9642-9657. [CrossRef]

27. Chen, Y.; Yang, K.; Qin, J.; Zhao, L.; Tang, W.; Han, M. Evaluation of AMSR-E retrievals and GLDAS simulations against observations of a soil moisture network on the central Tibetan Plateau. J. Geophys. Res. Atmos. 2013, 118, 4466-4475. [CrossRef]

28. Kim, Y.; Kimball, J.S.; Du, J.; Glassy, J.M. Improvements and Extension to a Global Earth System Data Record of Daily Landscape Freeze-Thaw Status Determined from Satellite Microwave Remote Sensing; University of Montana: Missoula, MT, USA, 2014.

29. Imaoka, K. Jaxa Agency Report; Earth Observation Research Center (EORC) Japan Aerospace Exploration Agency (JAXA): Tokyo, Japan, 2016.

30. Parinussa, R.M.; Holmes, T.R.; Wanders, N.; Dorigo, W.A.; de Jeu, R.A. A preliminary study toward consistent soil moisture from AMSR2. J. Hydrometeorol. 2015, 16, 932-947. [CrossRef]

31. Du, J.; Kimball, J.S.; Shi, J.; Jones, L.A.; Wu, S.; Sun, R.; Yang, H. Inter-calibration of satellite passive microwave land observations from AMSR-E and AMSR2 using overlapping FY3B-MWRI sensor measurements. Remote Sens. 2014, 6, 8594-8616. [CrossRef]

32. Ke, Y.; Leung, L.; Huang, M.; Coleman, A.M.; Li, H.; Wigmosta, M.S. Development of high resolution land surface parameters for the community land model. Geosci. Model Dev. 2012, 5, 1341-1362. [CrossRef]

33. Song, C.; Jia, L.; Menenti, M. Retrieving high-resolution surface soil moisture by downscaling AMSR-E brightness temperature using MODIS LST and NDVI data. IEEE J. Sel. Top. Appl. Earth Obs. Remote Sens. 2014, 7, 935-942. [CrossRef]

34. Xue, H.; Wang, J.; Xiao, Z.; Chen, P.; Liu, Y. Combining modis and AMSR-E observations to improve MCD43A3 short-time snow-covered albedo estimation. Hydrol. Process. 2014, 28, 570-580. [CrossRef]

35. Parinussa, R.M.; Lakshmi, V.; Johnson, F.; Sharma, A. Comparing and combining remotely sensed land surface temperature products for improved hydrological applications. Remote Sens. 2016, 8, 162. [CrossRef]

36. Shwetha, H.; Kumar, D.N. Prediction of high spatio-temporal resolution land surface temperature under cloudy conditions using microwave vegetation index and ANN. ISPRS J. Photogramm. Remote Sens. 2016, 117, 40-55. [CrossRef]

37. Du, J.; Kimball, J.S.; Azarderakhsh, M.; Dunbar, R.S.; Moghaddam, M.; McDonald, K.C. Classification of Alaska spring thaw characteristics using satellite L-band radar remote sensing. IEEE Trans. Geosci. Remote Sens. 2015, 53, 542-556.

38. Roy, A.; Toose, P.; Williamson, M.; Rowlandson, T.; Derksen, C.; Royer, A.; Berg, A.A.; Lemmetyinen, J.; Arnold, L. Response of L-band brightness temperatures to freeze/thaw and snow dynamics in a prairie environment from ground-based radiometer measurements. Remote Sens. Environ. 2017, 191, 67-80. [CrossRef]

(C) 2017 by the authors. Licensee MDPI, Basel, Switzerland. This article is an open access article distributed under the terms and conditions of the Creative Commons Attribution (CC BY) license (http://creativecommons.org/licenses/by/4.0/). 